ISSN: 0213-3563

https://doi.org/10.14201/azafea202123277306

\title{
COMPROMISO Y DESTINO EN LA OBRA ENSAYÍSTICA DE RAMÓN GAYA
}

\author{
Commitment and Destiny in the Essayistic \\ Work of Ramón Gaya
}

Inmaculada Murcia SERRANO

Universidad de Sevilla (España)

Recibido: 21 de septiembre de 2020

Aceptado: 11 de marzo de 2021

\section{RESUMEN}

Mi interés en este trabajo consiste en explicar cómo se concilian el compromiso político y el artístico en el caso del poeta, pintor y ensayista Ramón Gaya, vinculado por generación y por ideología a la generación del 27. Gran defensora de la "deshumanización del arte", aquella generación tuvo que adaptar sus planteamientos artísticos originales a una situación histórica determinada por la Guerra Civil, y cada representante encontró una solución al conflicto subsecuente entre el ámbito de la política y el del arte. El objetivo es también fundamentar con una amplia contextualización histórica el origen de la actitud concreta de Gaya ante tal contradicción.

Palabras clave: Ramón Gaya; generación del 27; pureza; compromiso; destino.

\section{ABSTRACT}

My interest consists in explaining how political and artistic commitment are reconciled in the writtings of the poet, painter and essayist Ramón Gaya, linked by generation and by ideology to the Generation of 27. As a great defender of the "dehumanization of art", the Generation of 27 had to adapt their original artistic approaches to a historical situation conditioned by the Civil War, and each representative found a solution to the conflict between politics and art. The objective is also to base the origin of Gaya's attitude with a broad historical contextualization referred to artistic situation. 
Key words: Ramón Gaya; Generation of 27; purity; commitment; destiny.

En una sola cosa me siento cada vez más fuerte: mi pintura. Y cada vez me siento más comprometido.

Es una alegría sentir que no somos libres.

Sí, gracias a Dios, no tenemos esa monstruosidad vacía que se llama Libertad.

Carta de Ramón Gaya a María Zambrano, México, 24 de junio de 1949. (2018, p. 28)

\section{INTRODUCCIÓN}

En una carta que envía María Zambrano al pintor Ramón Gaya en mayo de 1959, la filósofa malagueña le hace saber que, después de haber visitado una de sus muestras artísticas, entrevé la llegada del pintor a un "ancho presente", a un tiempo que no se consume, que calla, y que demuestra cómo todo lo que Gaya crea nace de algo semejante a una ley, aunque una ley en la que "la libertad es obediencia" y "el conocimiento, amor". La paradoja no exime a la caracterización zambraniana de la pintura de Gaya de una férrea lógica interna. Como intentaré mostrar en este trabajo, literalmente, para Gaya, la pintura es obediencia libre a una ley, y ese acatamiento voluntario constituye además el único compromiso que incumbe el artista. El destino que se debe cumplir no es pues mera fatalidad, sino, paradójicamente, estricta y pura libertad.

Los términos "compromiso" y "destino" referidos a la obra del artista murciano se mencionan también en otra carta que envía Juan Gil-Albert a

1. Se trata de una carta fechada el 8 de mayo de 1959 en el Café Greco y en donde se lee, citando al completo el párrafo: “Porque has llegado ya 'al gran tiempo' -a veces lo he llamado 'ancho presente'- pero ahora encuentro más justa esa denominación. Todo lo que anoche contemplé ha nacido, se ha realizado en el gran tiempo, que es desde luego mucho tiempo, pero no sólo eso. Pues hay cuadros, libros... que consumen tiempo, pero no ése, el ancho, el grande, el circular". Y más adelante: "Y aunque, si estando así, pasaras mucho tiempo sin trabajar -ya sé que no es posible- estaría tranquila por ti. Que lo que estás haciendo es maravilloso. Pero lo es porque viene, nace de algo más maravilloso todavía. Es la Ley. Que es el logro total lo que veo; el grande tiempo donde se respira, donde la libertad es obediencia y el conocimiento amor; donde se perdona y se es perdonado. Tu Magdalena -flor- de ese definitivo perdón” (2018, pp. 86-87). 
Ramón Gaya a finales de octubre de $1969^{2}$. En este caso, los vocablos subrayados hacen referencia a una labor relacionada con la creación artística, no con la implicación política o ideológica, y eso a pesar de que los interlocutores de la carta -Gil-Albert y Gaya- fueron ejemplos de intelectuales comprometidos en ese otro sentido, como lo demuestra su participación en diversas actividades a favor de la causa republicana durante los años treinta y las trágicas consecuencias que, terminada la Guerra Civil, les supuso aquella involucración.

“Destino” es, por lo demás, una palabra que usa Ramón Gaya -como, por cierto, también María Zambrano- en uno de sus textos más conocidos y afamados, quizá el más importante de su producción estética, El sentimiento de la pintura. Allí la emplea para definir el concepto mismo de Arte (escribámoslo con mayúsculas), desplazando a un segundo plano otras particularizaciones más conocidas de este escurridizo concepto, como las que lo asocian con la belleza, la moralidad, la expresión, la imaginación, la mímesis o la abstracción, que copan, con su sola mención, siglos enteros de reflexiones estéticas. Para Gaya, el Arte es, antes que todo eso, Destino, y, como tal, al artista no le queda más remedio que escucharlo y, sobre todo, cumplirlo. De ahí que el compromiso artístico real que adquiere el artista sea, en efecto, el que contrae única y exclusivamente con una instancia: el Arte. Cuando este compromiso se consuma, el arte alcanza su destino.

Que este sea el significado del término "compromiso" y también el propio compromiso personal adquirido por Ramón Gaya -adquirido y expresado, pues, en términos estrictamente estéticos-, puede resultar inconcebible y hasta incómodo para quienes no quieren o pueden entender la radicalidad con la que determinados artistas viven, experimentan y sienten su propia creación; puede resultar también inadecuado y controvertido, pues cabe la posibilidad de que se (mal)entienda que su asunción conlleva la desestimación de otros aspectos extraartísticos de sus biografías que demuestran, por el contrario, compromisos ideológicos y políticos paralelos. Mi interés en este trabajo consiste en explicar cómo se concilian el uno y los otros en el caso concreto de Ramón Gaya: hasta dónde llega el compromiso político del

2. La carta está fechada el 30 de octubre de 1969 en Valencia, y en ella puede leerse lo siguiente: "Nuestra situación se ha inmovilizado definitivamente, casi podría decirse que vivimos con los recursos de los pájaros, sólo que sin alas. No me quejo; todo parece tener un sentido oculto, y yo, rebelde en tantas manifestaciones juveniles, acato ese impenetrable azar que nos rige. Por eso, esencialmente, tus dos libros me conmueven, porque están repletos de compromiso y de destino" (2018, p. 207). 
hombre de carne y hueso y el artístico del creador; en qué punto se tocan o se repelen; y cómo el mismo pintor, si es el caso, llegó a reconciliarlos y justificó, para él o para otros, esa reconciliación.

Hay un artículo breve de Rafael V. Orden Jiménez que aborda ya esta misma cuestión y en el que se explicita que la palabra "destino", en el caso en concreto de Ramón Gaya, ha de ponerse en relación con la palabra hermana de "vocación". Como bien se explica en este trabajo, el destino lo constituyen fundamentalmente aquellas circunstancias biológicas, geográficas, familiares, económicas o socio-políticas que definen el marco dentro de cuyos márgenes se ha de desplegar la vida; la vocación es, en cambio, aquello que uno reconoce como su proyecto de vida y a cuyo cumplimiento se siente llamado a obedecer si lo que se desea es una vida dichosa. Des-dichado es, entonces, quien no reconoce su destino, pues, en tal caso, no identificará la vocación que le conviene y acabará habitando en una vida irreal; y des-dichado es también quien, identificando su destino, se niega a aceptarlo como vocación, en cuyo caso construirá una vida ficticia. Según Orden Jiménez, esto es de lo que trata el texto de Gaya titulado "El extremoso deber del artista", en donde se pone en pie la idea de que el destino es deber y la vocación compromiso (2011, pp. 11-14). Enormemente sugerente, este trabajo de Orden Jiménez se limita a exponer la idea que aquí va a servir de guía, pero apenas profundiza y contextualiza histórica e intelectualmente lo que significó la vocación pictórica concreta de Ramón Gaya, su "compromiso" con el arte, y, en paralelo, su otro compromiso aceptado igualmente como destino, el que aquí voy a denominar "compromiso material” y que a Gaya le condujo a admitir, sin alternativas posibles, la condición de exiliado. Mi objetivo es también fundamentar con una amplia contextualización histórica el origen de esta actitud ante la política y ante el arte, porque sólo se entiende la actitud de Gaya a la luz de lo que estaba ocurriendo, en esos planos, a su alrededor.

\section{El PAPEL Y LA SITUACIÓN DEL ARTE ANTES Y DURANTE LA CONTIENDA BÉLICA DEL 36}

Antes de entrar a analizar el caso concreto de Ramón Gaya y de lo que él entendía por "compromiso", "destino" o "vocación”, conviene contextualizar sus argumentos revisando cuál era la situación estética del momento, especialmente, en los albores de la Guerra Civil, que es cuando la cuestión del "compromiso" del artista adquiere mayor relevancia. Suscribo las palabras 
de Miguel A. Gamonal -a quien seguiré en este trabajo previo de contextualización, puesto que ha estudiado con detenimiento esta parte de la historia española del arte- cuando afirma que los productos artísticos generados durante la República y la Guerra Civil deben ser analizados como se merecen, sin sobrevaloraciones políticas ni subvaloraciones esteticistas $(1987$, p. 17).

Quizás con demasiada frecuencia se ha hablado de la existencia de una intelectualidad republicana homogénea, lo cual no deja de ser un mito. En lo que a la cultura artística respecta, se puede decir que hubo fundamentalmente dos grupos que intervendrían activamente en el debate sobre el papel del arte ante la Dictadura de Primero de Rivera, primero y, especialmente, en lo que vendría después, si bien sus ideas no son tampoco estáticas o impermeables a ideas distintas: por un lado, estaría la Generación del 27 y su órbita de influencia, en su mayor parte, defensora del purismo poético, aunque con matices; y, por otro lado se situaría la que Ana Bundgaard, acuñando un término de María Zambrano, propone designar como "generación de 1930” o "generación del toro", por haber sido "sacrificada" por la historia (2009, p. 51). Esta segunda generación reviste una complejidad remarcable porque entre sus miembros se cuentan intelectuales muy comprometidos políticamente pero que separan lo estético de lo social, entrando a veces en complejas contradicciones de costosa solución. A este grupo podemos considerar que pertenece Ramón Gaya.

A la complejidad que estos dos grandes grupos trae consigo, hay que añadir el hecho de que, en aquel convulso momento, la cultura se transformara, en la zona republicana y ya durante la Guerra Civil, en un verdadero sustitutivo de la religión. Su difusión y defensa fueron, de hecho, un lugar común, hasta el punto de convertirse incluso en otra suerte de mito y en uno de los temas más espectacularmente trabajados por escritores y artistas de distinta procedencia. No hay que olvidar que, en buena medida, aquella cultura republicana era, más bien, propaganda, lo que provocó que se difuminaran los límites entre política y creación. Se ha llegado a decir por eso que la Cultura -con mayúscula- se convirtió en la más importante baza propagandística del gobierno republicano, el gran tótem sobre el que edificar la conciencia de una unidad en tiempos de penuria, hasta el punto de identificar el término, directamente, con la propia República. Esta identificación sigue atrayendo hoy día a muchos simpatizantes de esta opción, como han mostrado algunos estudiosos (Gamonal, 1987, pp. 17-18). Pero lo que interesa subrayar es que esa Cultura, instrumentalizada y fuertemente ideologizada, ligada directamente a las instancias políticas y al poder, venerada incluso religiosamente, 
constituye el imprescindible trasfondo sobre el que hay que estudiar las actividades artísticas realizadas en esta época de la historia de España. Quizás los mejores representantes de esta otra deriva intelectual, la afín a lo que podemos llamar, usando el término orteguiano, "culturalismo" republicano, fueran los intelectuales evacuados de Madrid entre noviembre y diciembre de 1936 y afincados en Valencia hasta el final de la contienda; en ese grupo se encuentra Ramón Gaya. A partir de aquel año, la ciudad mediterránea vio nacer una suerte de Parnaso efímero, en el que justamente terminó su misión la más emblemática de las publicaciones culturales republicanas, Hora de España, y desde esa ciudad pusieron punto y final a la vida que habían gozado en su país muchos de los miembros de la "generación del toro", quienes, en un excesivamente breve pero intenso período de tiempo, pasaron a convertirse en exiliados. Este grupo, pese a su aparente homogeneidad, no se libró de fricciones ideológicas y estéticas con el mismo Ministerio de Instrucción Pública, que estaba por entonces bajo el mando del Partido Comunista. Mostraré estos conflictos de manera más detallada a lo largo de la investigación. Me interesa, de momento, poner de manifiesto la complejidad de la situación estética, artística y cultural del momento, incluso en lo que se refiere al caso del frente popular republicano, y subrayar así lo falso que resulta simplificar sus postulados artísticos, políticos o ideológicos en general.

No por centrar nuestra atención en el bando republicano hay que ignorar el hecho de que, en el bando nacional, ocurriera algo similar, aunque materializado en propuestas creativas de muy distinta índole. También en este otro lado se dio origen a "nuevas mitologías", por usar la expresión romántica, en particular, la del Imperio y la de la defensa de la religión, sobre las que los intelectuales nacionalistas fundamentaron cierta unanimidad que pretendía aunar conciencias y colectividades (Gamonal, 1987, pp. 17-18). En este trabajo, sin embargo, no nos interesa analizar el papel del arte y de la estética en el bando nacional, asunto que nos llevaría muy lejos. La postura ideológica de Ramón Gaya es clara a este respecto, y, en todo caso, lo que se pretende despejar es en qué medida fue posible, para este autor en concreto, compaginar compromiso intelectual y artístico con compromiso político y material. 
3. LOS COMPROMETIDOS POLÍTICAMENTE Y LOS PURISTAS ARTÍSTICOS. ¿UNO O DOS GRUPOS DIFERENCIADOS?

Empezaré revisando brevemente el grupo de intelectuales que se pueden considerar comprometidos tanto política como artísticamente con la causa republicana. En la época en la que me sitúo, el ambiente está sin duda máximamente politizado y ello crea el caldo de cultivo para la efervescencia de lo que se ha dado en denominar, de manera hartamente vaga, "literatura comprometida". Se suelen nombrar como representantes de esta tendencia literaria al peruano César Vallejo, que se encuentra en España cuando se proclama la II República; o a Ramón Pérez de Ayala, director del Museo del Prado durante el gobierno republicano. Para muchos artistas de esta facción, la vanguardia empieza a ser vista como una moda trasnochada y condenable por su aparente insensibilidad social y política. Se discute la función del artista en la sociedad y se piensa que la poesía debe arrancar del pueblo, dejar de ser aristocrática y minoritaria y reorientarse hacia las masas. Como dice el estudioso de la literatura española Juan Cano Ballesta, cierto pensamiento materialista y de izquierda - ciertamente, no todo- acusa al "arte puro" de delito de alta traición y trata de convertir al artista en un celoso propagandista (1972, capítulo II). Por su parte, en palabras de Ana Bundgaard:

Todas estas corrientes artísticas cristalizan en una teoría de la literatura comprometida que propugna el engarce entre lo individual e íntimo y lo social e histórico. Se trata de una visión del arte que reivindica la presencia de lo popular en la literatura, aunque desde diversas ópticas y posturas. (2009, p. 63)

Si nos centramos en el ámbito de las vanguardias, es fácil constatar que, tras la aparición del Segundo Manifiesto Surrealista en 1929, mucho más ideologizado que el primero, entra en crisis el ideal de la "pureza" y la "deshumanización”: lo humano e, incluso, lo social y lo político se arrogan buena parte del protagonismo. Ejemplos de la evolución "de la vanguardia al compromiso” pueden ser los poetas Federico García Lorca y Rafael Alberti, aunque este último, claro militante comunista, tampoco se vio del todo libre del conflicto que encontraba entre la lucha política y el compromiso estético, experiencia que definió con longeva fortuna como un situarse "entre el clavel y la espada" (Bundgaard, 2009, p. 191).

En este grupo artístico máximamente politizado, podemos situar también la llamada "literatura de avanzada", que bebe directamente de las consignas 
ideológicas de la revolución bolchevique y busca, por eso, "despertar" a las “masas” para la lucha emancipadora de toda opresión y explotación. No por casualidad, a partir de 1930, la palabra "compromiso" llega a ser clave entre los artistas españoles de este grupo en particular. Ese año se produce la destitución de Primo de Rivera y el general Berenguer es designado para formar gobierno. Refulge entonces el sentimiento republicano frente a la monarquía y se produce la conversión masiva a esta opción política por parte de autores clave como Azaña, Ortega y Unamuno, autoridades intelectuales cuyas palabras son oídas por multitud de artistas e intelectuales (Bundgaard, 2009).

Un concepto acuñado en estos momentos para el teatro, el arte de urgencia o, también, agit-prop (Cobb, 1992-93), sirve igualmente de ejemplo de esta tendencia artística fuertemente politizada, para la cual el artista debe prescindir de cualquier tipo de prejuicio estético y hacer arte al filo del combate, en la trinchera. Entre los requisitos que se exigen para conseguirlo cuentan el abandono del elitismo y del perfil característico del artista burgués, que, pese a las contradicciones personales que les pudiera ocasionar-dada la procedencia, por lo general, burguesa de muchos de los artistas mencionados-, había de ponerse al servicio del pueblo. En esta línea podemos citar a autores como María Teresa León, la María Zambrano de Los intelectuales en el drama de España, Lorenzo Varela, que llegaría a ser comandante de la brigada de la undécima división, etc. Muchos de estos intelectuales escribirían también en una de las publicaciones más cercanas ideológicamente al compromiso intelectual sin concesiones, El mono azul, en el que se definió el militantismo estético llevado ya sin miramientos al plano de la propaganda política ${ }^{3}$. Algunas voces extranjeras avivan este sentimiento de compromiso político entre los artistas españoles, como ocurre con el muralista mexicano David Alfaro Siqueiros y el dramaturgo alemán Erwin Piscator. Ciertamente, como ha escrito Gamonal, dentro de este grupo pareciera que el artista español había perdido cualquier prurito estético; incluso pareciera haberse extendido el acto de defunción del arte por el arte o arte puro, para plantearse como único horizonte creativo el de la utilidad ideológica y política inmediata, o el de la semejanza directa entre las armas y las letras (1987, pp. 54-55).

Esta puede ser la impresión que exhala la época, en efecto, pero no necesariamente debe ser considerada la realidad. Y esto es justo lo que interesa

3. Lo mismo ocurrirá, aunque quizás con menos vehemencia, en las páginas de la revista catalana Mirador, en las que escriben el pintor Joan Commeleran, Antoni Gago, Ferrán Planes o el también artista plástico Ángel López-Obrero. 
ENSAYÍSTICA DE RÁMON GAYA

subrayar en este apartado de la investigación. A pesar del auge de los artistas comprometidos, de las propuestas concretas de agitación y pese a la crispación política del momento -tan propicia para el desvanecimiento de la vanguardia-, lo cierto es que la batalla contra la poesía pura que este grupo parece emprender no llega a ningún final victorioso. Aparte del prestigio que, en plena época de convulsión política, siguen gozando Paul Valéry o Juan Ramón, adalides de la pureza poética, muchos escritores continúan divulgando textos a favor de ella. Enrique Azcoaga, en un ensayo publicado en Hoja literaria en abril de 1933 y titulado "Sentido social del poeta. Fragmentos", contrapone poesía y sociedad. Parte de la idea de que el poeta es un ser "solitario", como decía Mallarmé, y que ligarse a la sociedad es aniquilarse como artista. Melchor Fernández Almagro y Arturo Serrano Plaja también se niegan a aceptar esta politización artística (Cano Ballesta, 1972). Volveré más adelante sobre este último escritor por su importancia para la comprensión de la situación del arte en la España de la contienda y, por extensión, del punto de vista adoptado por Ramón Gaya. Se puede decir como conclusión que pocas veces sonó tan rotunda la máxima orteguiana de que el poeta empieza donde el hombre acaba.

Ramón Gaya también debe ser incluido en este subgrupo dentro de los comprometidos ideológicamente. Como se verá con más detenimiento, será él uno de los artistas que más se resista a la oleada de compromiso político que atiza durante esos años a los artistas y poetas de su generación. Como otros muchos compañeros, Gaya seguirá preso de los preceptos estéticos que se derivan de la asunción del purismo artístico y que traen consigo la acusación de "inautenticidad" e incluso de "traición" a todo producto que los transgreda. Juan Cano Ballesta considera que el prejuicio de la impureza, que Gaya sin duda posee, estaba fuertemente arraigado en la cultura de la época y que se requería un gran esfuerzo para erradicarlo ${ }^{4}$. Ello provocó una especie de cisma estético, del que el pintor murciano constituye un ejemplo, que separó a los más implicados políticamente, de los que preferían mantenerse fieles a la poesía pura y que, en sentido inverso al proceso de politización del arte y pese a que políticamente también ellos eran artistas "comprometidos",

4. “Este enfoque artístico está tan arraigado en nuestro contorno cultural que se requiere un gran esfuerzo y un cambio de actitud muy profundo para aceptar del todo la idea de que la poesía puede mezclarse con la política. Ésta aparece como lo sucio, impuro, lo público, como la corrupción del arte, mientras que la poesía es lo limpio, íntimo, la quintaesencia de la belleza” (Cano Ballesta, 1972, p. 149). 
contribuyeron a perpetuar en España la vida en apariencia agónica del arte puro (Ballester, 2007).

Interesa, por tanto, subrayar que la producción cultural de los intelectuales y artistas defensores del régimen republicano, excepto del caso de los defensores declarados del realismo socialista, revela una discreta, aunque fuerte y nunca resuelta tensión entre las preferencias estéticas individuales y el compromiso ético con la comunidad. Por eso, no es posible afirmar sin reticencias el postulado o prejuicio ampliamente difundido de que los escritores que apoyaban a la República defendían de forma unánime una poética sometida al compromiso político al servicio del pueblo. Ana Bungaard lo ha estudiado a fondo y lo ha resumido así:

El compromiso fundamental de los escritores y artistas de excelencia fue el que tuvieron con la libertad para crear cultura, según una estética que no querían supeditar a cánones políticos. Exponentes de esta actitud comprometida, y a la vez artística, son casi todos los miembros de la llamada generación del 27. La "causa" con la que ante todo se sentían comprometidos los poetas de ese grupo fue en primer término una "causa" intelectual de naturaleza estética, a la que supeditaron después, el compromiso social y político. A pesar de su coyuntural alineamiento ideológico bajo el Partido Comunista en los años de la Alianza de Intelectuales Antifascistas, esos escritores nunca sujetaron la creación artística a los dogmas del realismo socialista de inspiración soviética. (2009, p. 191)

La tensión entre el polo del compromiso estético y el del compromiso político material se hace notar, entonces, en muchos de los poetas de la órbita del 27, en particular en los colaboradores de la revista Hora de España. Aunque es cierto que estos poetas rompieron con el vanguardismo y "rehumanizaron" la llamada poesía pura y "deshumanizada”, no renunciaron nunca a la defensa de la libertad estética. Es importante recalcar esta cuestión. Quizás uno de los mejores ejemplos de esta posición sea el poeta Luis Cernuda, quien, a pesar de ser militante del Partido Comunista, hizo declaraciones que exhibían su convicción de que la poesía era una cosa y la política otra. Para él, como para muchos otros creadores, el "reparto de funciones", en expresión de Bundgaard, entre política y creación artística tenía como objetivo impedir la degradación de la calidad estética que muchos entendían como amenaza derivada del seguimiento sin concesiones del realismo socialista, que se antojaba a su vez como un verdadero dogma estético (Bundgaard, 2009, pp. 198199). Otro caso reseñable es el del escritor y poeta Juan Gil-Albert, quien 
defendería igualmente y también en Hora de España la libertad de expresión artística y criticaría la pertinencia del arte realista (Gamonal, 1987, p. 57). $\mathrm{La}$ actitud de estos dos escritores, que era la propia de casi todo el grupo, se reflejará de manera ampliamente argumentada y lúcidamente escrita en la "Ponencia colectiva", que, firmada por muchos de ellos, se presentó en el II Congreso Internacional de Escritores y Artistas en Defensa de la Cultura. Volveré también sobre este importante documento. Por ahora, puede afirmarse que Ramón Gaya mostró igualmente su disconformidad con la politización y la supuesta y demagógica colectivización del arte. María Zambrano, extremadamente comprometida en sus artículos de perfil político publicados en El mono azul, dudaría también de que el marxismo dejase mucho lugar a la creación. Finalmente, Sánchez Barbudo, por citar otro caso paradigmático, intentaría encontrar un equilibrio imposible en un mundo poco propicio a matizaciones, ya que se le antojaba harto complicado casar arte de vanguardia con realismo soviético, para él, enormemente homogéneo (Gamonal, 1987, p. 57).

Queda suficientemente constatado, así, el más bien escaso acogimiento que el realismo soviético entendido como ideal o precepto estético del compromiso tuvo entre los artistas españoles de los años treinta, así como las difíciles relaciones habidas en aquellos años entre vanguardia artística y vanguardia política. De nuevo hay que insistir en la complejidad estética exhibida por parte de los creadores que simpatizaban políticamente con el bando popular. A lo dicho anteriormente hay que sumar un factor de cariz psicológico que incrementó todavía más el conflicto entre uno y otro polo del compromiso. La idea la ha puesto en pie Gamonal, siguiendo una idea de Gramsci, al advertir que en España, los intelectuales habían conseguido una "hipervaloración" social (2014, pp. 169-190) y que, "encerrados en la propia cárcel de su elitismo, con la mala conciencia de la relación con el pueblo, convencidos de su propia utilidad al servicio de la causa popular, concibieron una mítica unión con el pueblo que pronto tendría que llegar a chocar con los propios postulados de las exigencias estéticas" (1987, p. 57). Ello explicaría la súbita aparición del romancero, difícilmente encuadrable ni en la poesía pura, ni en la vanguardia; y a ello hay que sumar igualmente la irrupción del cartelismo como única salida aparentemente honrosa y paralela al romancero literario para el caso en particular de los artistas plásticos, quienes, atrapados igualmente en las consignas vanguardistas de la pureza, se vieron obligados a buscar formas alternativas de salvar el hiato entre elitismo artístico y mística popular (Gamonal, 1987, p. 57). Dado que el caso que nos ocupa es el de un 
artista plástico, aparte de poeta y ensayista, es conveniente profundizar más en la casuística estética del cartelismo y en su relación con las artes plásticas tradicionales, en particular, con la pintura, en cuyas relaciones es posible ver reflejado el mismo conflicto que aqueja a los escritores comprometidos ideológicamente con el socialismo y artísticamente con la pureza y la vanguardia poética y “deshumanizada”.

\section{LA CUESTión de la PROPAGANDA POLÍtica, LAS ARTES PLÁstiCAS Y EL CARTELISMO EN LA ESPAÑA DE LOS AÑOS 30}

Es posible comenzar con una afirmación que, llegados a este punto, ya no debe resultar sorprendente. El grupo de intelectuales comprometidos con la pureza artística mantuvo por lo general una distancia crítica y muchas reservas estéticas con respecto a la propaganda política realizada a través del cartel y el diseño gráfico. Uno de los vehículos fundamentales de este distanciamiento de los artistas fue, de nuevo, la revista Hora de España, principal medio de difusión del parnaso purista mediterráneo, como ya se ha comentado. Para muchos de sus colaboradores artistas, como el propio Ramón Gaya, la producción plástica orientada a la propaganda se veía aquejada, no ya sólo del utilitarismo circunstancial propio de una contienda bélica -utilitarismo que, para un defensor de la pureza, constituía una especie de blasfemia-, sino incluso, yendo más allá, de precipitación, falsa heroicidad y cierto patetismo. El problema es, no obstante, más complejo, ya que tenía que ver también con que los artistas que se dedicaron a realizar estos diseños apenas disponían de otras posibilidades de expresión, si descontamos la Exposición de París de 1937 y los concursos y exposiciones promovidos por el Ministerio de Instrucción Pública, también fuertemente politizados. No hay que olvidar que el Ministro de Instrucción Pública en el período bélico, Jesús Hernández Tomás, convirtió su cartera en una verdadera plataforma de propaganda en la que muchas veces se confundían el plano de las instituciones estatales con los intereses partidistas. Hernández sustentó su política cultural en la plataforma artística creada por la Alianza de Intelectuales Antifascistas, a la que se volverá más adelante (Gamonal, 1987, p. 23).

Puede decirse que las instituciones políticas suplen en este momento el papel de las galerías y centros de arte, lo que desencadena la progresiva sustitución de la pintura de caballete y de la escultura, por los diseños gráficos y el dibujo. Y puesto que estas otras prácticas se enfocan claramente a fines 
de adoctrinamiento político, la vanguardia pictórica, como la literaria, parece también condenada a desaparecer. Como apunta Gamonal, "en los primeros meses de la guerra, con una cultura volcada unánimemente hacia la propaganda, la posible banda de opciones estilísticas y expresivas se va a estrechar hasta lo inverosímil” (1987, p. 32). No por otra razón, las exposiciones artísticas del momento se llenan de carteles, dibujos de guerra, periódicos murales y todo tipo de objetos propagandísticos no siempre dotados de cualidades estéticas. Está por eso claro que, para bien o para mal, el cartel político constituye el elemento más representativo de la producción plástica de la Guerra Civil española, al menos, en lo que se refiere al campo republicano (Gamonal, 1987, p. 37). A ello hay que sumar las distintas exposiciones organizadas fuera de España con objeto de recaudar fondos o llamar la atención sobre la causa política de izquierdas. Ahí, sí, curiosamente, siguen haciendo aparición los artistas académicos, y la temática de las obras no suele presentar contenido bélico, aunque sus fines recaudatorios nos obligan a considerar estas actividades como igualmente propagandísticas. Las vanguardias solo tienen hueco en el Pabellón Español de la Exposición de París de 1937, aunque tampoco en este caso se puede decir que sus intenciones fueran políticamente neutrales (Gamonal, 1987, p. 32). No es de extrañar, entonces, que buena parte del debate en torno a las artes plásticas en la Guerra Civil se moviera en torno a una sola cuestión: la conveniencia del arte de propaganda y la resistencia o adhesión a las directrices político-artísticas ideológicamente afines a cada artista en particular, sobre todo las que venían dictadas por el realismo socialista (Gamonal, 1987, p. 53).

Así pues, la necesidad de muchos artistas plásticos españoles de dar salida a su creatividad por alguna de las vías propias de la propaganda fue vista por los intelectuales puristas y por muchos creadores como una caída en una suerte de alienación artística, claramente opuesta a los fines liberadores que, desde cierta perspectiva estética, se le atribuían al Arte, de nuevo con mayúsculas. De alguna forma, desde esa perspectiva, los pintores y escultores parecían haber perdido la dignidad. Es lo que insinúa el único número publicado de la revista El buque rojo, antecedente directo de Hora de España: "EL Buque Rojo aspira a presentarse con la dignidad artística y literaria que han alcanzado los artistas y poetas de siempre cuando, al sincerarse con honda humanidad y modestia, han logrado comunicarse con el pueblo o revelar al pueblo con sus propios anhelos" (cit. Gamonal, 2014).

Ni siquiera el tópico romántico de la comunión con el pueblo limará las reticencias que los puristas exhiben en contra de la utilidad y necesidad del 
arte de propaganda, su política y tecnocrática "efectividad”, equiparada, por algunos de sus defensores, a los fusiles y los cañones. Es más, podría decirse que la situación del arte en la España de esta época puso en evidencia las muy laxas fronteras que separaban en realidad el populismo político de la mística popular. Este interesante dúo y sus inestables fronteras merecerían más atención de las que se le dispensarán aquí, pues no es el objetivo de este trabajo. Puede indicarse, con todo, cómo el propio Ramón Gaya se percata de muchas de esas contradicciones internas que acarrean los dos tipos aparentemente irreconciliables de "compromiso" del intelectual: por ejemplo, hace ver que el realismo preconizado por los comunistas no garantiza la legibilidad o el entendimiento artístico por parte de las clases populares, y lo hace ver con conocimiento de causa, ya que él lo ha experimentado en persona en sus colaboraciones con las Misiones Pedagógicas, que, en principio (y se matizará más adelante), pueden considerarse como un ejercicio de mística popular. No es de extrañar que Gaya ensalzara -con Bergamín y Gasch- las posibilidades políticas que tenían justamente otros estilos artísticos contrapuestos al realista, como lo demostraba, por poner un ejemplo incontestable, El Guernica de Picasso, de estilo cubista pero no por eso incapaz de expresar el dolor intrínseco a cualquier tipo de contienda.

Josep Renau es en ese momento el más prestigioso cartelista español que, además, escribe sus ideas y puntos de vista políticos, ideológicos y estéticos en documentos de enorme trascendencia para la estética española del siglo XX, como su Función social del cartel (1937). Su papel e influencia en el debate artístico español durante la Guerra Civil es determinante si tenemos en cuenta que se hizo cargo de la Dirección General de Bellas Artes. El texto mencionado resulta fundamental para comprender la posición artística oficial, afín a la propaganda, así como sus intentos esforzados por dignificarla artísticamente. El texto es también muy relevante para comprender por negación la postura que defenderá Ramón Gaya, no en vano contrincante ideológico en un famoso intercambio de cartas del primer número de la revista Hora de España.

En Función social del cartel, Renau expone su particular concepción del realismo, discute ideas diversas sobre los fines del arte político, argumenta su apreciación de la producción artística del momento y, como ya se ha indicado, exhibe una cierta “mala conciencia” (Gamonal, 1987, p. 39) que le hace excretar del espectro artístico propagandístico -tan defendido por él-, a los técnicos publicitarios; de esta manera, Renau inaugura una nueva frontera estética entre la imagen política artísticamente “digna” y la “mera” imagen publicitaria, “detritus” de la creatividad. Se genera así un desplazamiento de 
la reputación del cartel, aparte de una sofisticación del espectro de posibilidades de las artes visuales, que, en el caso de Renau, llega a adquirir incluso nimbos románticos y míticos, al servir de parapeto para la conquista de una suerte de "estética de mayorías" o, también podríamos decir, de un arte "sincero" para las masas (Gamonal, 1987, p. 39). No en vano, proliferan en este momento carteles firmados, que transgreden la tradición incuestionada del carácter anónimo del cartelismo. Y proliferan estos carteles de autor porque, como se ha venido indicando, a esta práctica han ido a desembocar, más por necesidad que por gusto, muchos artistas plásticos dedicados, antes de la contienda, al arte pictórico tradicional. Quizás el mejor representante sea el hoy día considerado uno de los mejores cartelistas españoles de la historia, José Bardasano Baos, cuyos carteles mantienen intacto el nivel de pulcritud y corrección académica pero emocionada de su obra pictórica prebélica (Gamonal, 1987, p. 42). Puede citarse también aquí a Ramón Gaya, quien, si bien no llegó a realizar carteles, sí que teorizó sobre el papel de artista y el cartelista en un conflicto bélico como el de España.

Interesa de momento destacar, para concluir este primer apartado, que la situación estética en la España de la época no puede resumirse en la mera discusión en torno a la dialéctica entre arte puro y arte comprometido; que lo que ocurre más bien es que el abanico estético se hace extremadamente complejo a la luz de los entrecruzamientos que se dan entre el compromiso político personal, las preferencias estéticas de cada uno de los artistas, sus necesidades de supervivencia, el lugar y el momento de concepción de sus creaciones, las directrices políticas que, en algunos casos, se ven obligados a seguir y otros muchos factores. Cualquier reduccionismo en este campo corre, por tanto, el riesgo de simplificar una tensión permanente y no siempre resuelta entre las fascinantes relaciones entre el arte y la política. El caso español de los años treinta no es en este sentido ninguna excepción.

\section{El compromiso en Ramón Gaya}

\subsection{Las misiones pedagógicas}

Visto el contexto en el que ha de entenderse lo que sigue, es posible comenzar esta segunda parte tratando de ahondar en lo que para Gaya pudo representar un verdadero conflicto entre compromiso artístico y compromiso político material. 
Para introducir dicha tensión se ha de tener en cuenta que Gaya participó en distintas iniciativas de cariz social y popular que se pueden considerar ideológicas o sesgadas políticamente. Ello demuestra que, en efecto, el pintor y poeta sostuvo un claro y fuerte compromiso material con el tiempo que le tocó vivir, y la mejor prueba de que así fue es su propia condición de exiliado, consecuencia de su defensa abiertamente reconocida de la causa republicana. Este apartado repasará las actividades políticas más importantes en las que se involucró Ramón Gaya hasta que se declara en España la Guerra Civil. Una de las más destacadas quizás sea las Misiones Pedagógicas, cuyo patronato fue creado por un Decreto del 29 de mayo de 1931, y con las que se pretendía conferir al arte un contenido educativo sencillo y al alcance de la mayor parte de la población rural. Concretamente, Gaya se encargó, junto a Juan Bonafé y Eduardo Vicente, de realizar copias de algunos cuadros del Museo del Prado destinadas a ser expuestas en un museo ambulante, cuya selección de obras corría a cargo de Manuel Bartolomé Cossío.

Que estas misiones eran, aparte de un ejercicio pedagógico-artístico, un acto político es algo que resulta indiscutible, aunque no siempre lo pareció. El decreto que les daba carta de nacimiento afirmaba que su finalidad era "llevar a las gentes, con preferencia a las que habitan en las localidades rurales, el aliento del progreso y los medios de participar en él, en sus estímulos morales y en los ejemplos de avance universal, de modo que los pueblos todos de España, aun los más apartados, participen en las ventajas y goces nobles reservados hoy a los centros urbanos" (Marín, 1990, p. 343).

El aspecto de las Misiones menos conocido y que más tiene que ver con el caso que nos ocupa es, como ya se ha mencionado, el Museo del Pueblo, al que se dedicó con ahínco Ramón Gaya. Nigel Dennis ha dejado amplio testimonio de esta actividad tan relevante para exponer y conocer el compromiso político del pintor murciano.

Como es bien sabido, Cossío era un gran aficionado al arte y asignaba un valor educativo muy especial a la experiencia estética. La idea de crear un museo circulante, dedicado a las grandes obras de la pintura española, formaba por eso parte del proyecto desde el momento mismo de su concepción. En concreto, el objetivo era llevar a los pueblos más aislados -como actividad paralela y complementaria de las del Coro y del Teatro- una muestra de lo mejor del patrimonio artístico nacional, concebido como legado cultural comunitario. Como solía decir Cossío, el "Museo del Pueblo" iba dirigido a todas aquellas gentes humildes 
que viven en las aldeas más apartadas, que no han salido de ellas o han salido sólo a las cabezas de partido, donde no hay Museos; que si han visto alguna estampa, no han visto nunca verdaderos cuadros; no conocen ninguna pintura de los grandes artistas. Quisieran las Misiones poder llevar este Museo a las aldeas más pobres, más lejanas y escondidas, como hasta ahora vienen haciendo con las demás cosas, porque para esos pueblos son principalmente las Misiones, para los desheredados. (Dennis, 2011, pp. 15-26)

La creación del Museo bajo los objetivos que acabamos de mencionar planteaba una dificultad práctica: la adquisición de las obras -es decir, de copias de cuadros importantes- que constituyeran la base de la colección. Cossío no quería que se utilizaran las reproducciones corrientes de la época y, con la ayuda de Pedro Salinas, miembro del Patronato desde su fundación, convocó a comienzos de 1932 un concurso para artistas copistas. Se presentaron varios pintores profesionales, entre ellos, tres pintores jóvenes que Salinas apreciaba especialmente y que consideraba más que aptos para emprender la misión. Me refiero a los ya citados Eduardo Vicente, Juan Bonafé y también Ramón Gaya 5 .

No se nombró a un "director” del Museo, pero los que se encargaban desde el comienzo y con más firme compromiso eran Gaya y Antonio Sánchez Barbudo. Los amigos que los acompañaban con más asiduidad fueron Rafael Dieste y Luis Cernuda. Se apuntaron, según la necesidad u oportunidad, otros colaboradores notables, entre ellos, Enrique Azcoaga, Arturo Serrano Plaja, María Zambrano y el imprescindible fotógrafo José Val del Omar, cuyas tomas fotográficas constituyen ya, al día de hoy, uno de los mejores testimonios del trabajo realizado por los misioneros.

5. Para el concurso, cada pintor eligió uno de los cuadros del Prado propuestos por Cossío: Gaya toma Los fusilamientos de la Moncloa, de Goya; Bonafé, la Resurrección, de El Greco; y Vicente, el Auto de fe, de Berruguete. Sus copias son aproximadamente del mismo tamaño que los cuadros originales. Ante el éxito de esta primera prueba, se les encarga a los mismos pintores copias de otros cuadros también seleccionados por Cossío. Se trata de obras de las máximas figuras de la pintura española: Sánchez Coello, Ribera, Zurbarán y Murillo, además de los ya mencionados Goya, Velázquez y El Greco. Gaya se hace cargo esta vez de El niño Dios Pastor, de Murillo; La infanta Margarita, de Velázquez; y Nevada, de Goya. Cabe mencionar también Pelele, de Goya, copiada por Eduardo Vicente; El sueño de Jacob, de Ribera, y la Maja vestida, de Goya, ambas copiadas por Gaya; Las hilanderas y Las Meninas, de Velázquez, copiadas por Bonafé; de Sánchez Coello, El retrato del Príncipe Don Carlos (de Gaya) y El retrato de la infanta Isabel Clara de Eugenia (este último sin datos del copista) (Dennis, 2011). 
El Museo solía abrirse por la mañana, entre las once y la una, para cualquier visita espontánea; luego más tarde, a partir de las cuatro, se ofrecían dos charlas al público, una que impartía Sánchez Barbudo, de carácter histórico, sobre la época a la que pertenecían determinados cuadros; y otra que daba Ramón Gaya, dedicada más bien a los cuadros mismos y a sus cualidades pictóricas (Dennis, 2011).

Resulta especialmente pertinente detenerse en el impacto que causó la labor de los misioneros, no sólo en las poblaciones que tuvieron oportunidad de visitar, sino en ellos mismos. Dennis considera que, para los misioneros, las experiencias compartidas entre 1932 y 1936 tuvieron una importancia decisiva. Durante aquellos cuatro años de "amistad errante" (la expresión es de Eugenio Otero), llegaron a conocer directamente el país, a comprender mejor la situación nacional, a consolidar su respeto por el pueblo y la cultura tradicional, e incluso a sentar las bases para la conducta ética individual, que se traduciría en un claro compromiso político y social puesto de manifiesto en esos y en los años venideros (Dennis, 2011). Por ello, resulta perfectamente legítimo hablar del "grupo de las Misiones", que más tarde, durante la Guerra Civil, volverá a unirse y a afirmarse justamente en la ya citada revista Hora de España. Esta es la razón por la que Dennis considera que el "impulso humanista" -el deseo de "restituir al hombre la integridad y la conciencia de su valor"- que caracteriza toda una vertiente de la vida cultural e intelectual de los años 30, tiene su más claro origen en la propuesta que representaron las Misiones Pedagógicas, idea que conviene retener en la memoria (Dennis, 2011). No resulta exagerado, por ello, sugerir que ese impulso humanista alcanza su máxima expresión en la "Ponencia Colectiva" leída en nombre de todos los miembros por Arturo Serrano Plaja en el Congreso de Escritores Antifascistas, celebrado en Valencia en julio de 1937. Se trata precisamente del segundo hito que querría señalarse aquí en relación al compromiso político de Ramón Gaya y su correspondencia con el compromiso y el destino artístico expresados por muchos intelectuales de su generación.

\section{La Ponencia Colectiva y el Congreso de Escritores Antifascistas}

Es difícil valorar si efectivamente la experiencia de las Misiones Pedagógicas tuvo repercusión directa en la famosa "Ponencia Colectiva", publicada en el número VIII de Hora de España (1937), pero sí puede afirmarse que el contenido de la misma marca un claro cariz a la estética del grupo y, en el 
caso de Ramón Gaya, una senda que ya no va a abandonar y que es justamente el camino en el que se perfila el que va a ser su compromiso artístico verdadero, más allá o por encima del político, ideológico o, como aquí se ha denominado, "material".

Algunos estudiosos opinan que nos encontramos ante uno de los mejores manifiestos producidos por los intelectuales españoles de la Guerra Civil en pro de la independencia estética y de pensamiento y en contra de la uniformidad del realismo socialista (Bundgaard, 2009). Podría añadirse que el texto constituye todo un manifiesto artístico reivindicable como testimonio de la complejidad estética española en los tiempos de la contienda. Se trata, en efecto, de un verdadero credo artístico-estético que no podía más que simpatizar con las perspectivas que ya Ramón Gaya estaba comenzando a desarrollar por aquellos momentos.

Resulta conveniente, primero, contextualizar la "Ponencia” y pasar, después, a analizar su contenido. Así, la Alianza de Intelectuales Antifascistas, en el seno de la cual se expuso públicamente, fue, como es bien sabido, una institución heredera de la organización de intelectuales que la política frentepopulista creó a partir del Congreso de Escritores Soviéticos de 1934, y del de París, en el año siguiente, para sustituir las antiguas secciones de artistas y escritores proletarios que aún daban testimonio de la existencia de alguna suerte de proletkult (Gamonal, 1987). Muy relacionada con las publicaciones de El Mono Azul y Hora de España, la Alianza tuvo un carácter claramente paraoficial, como transparenta la simbiosis que mostraba con el Ministerio de Instrucción Pública. Su cariz propagandístico es, por eso, claro ${ }^{7}$. La organización del II Congreso Internacional de Escritores Antifascistas será quizá su mayor éxito, aunque la labor de sus secciones de literatura, artes plásticas, teatro, bibliotecas, propaganda o pedagogía será también más que reseñable en los meses anteriores a la evacuación y el cerco de Madrid, en torno al mes de noviembre de 1936 (Gamonal, 1987, p. 29).

6. He dedicado un libro a poner en pie dicha trayectoria ideológica en materia artística. Véase Murcia (2010).

7. Así lo ha mostrado en su importante estudio Miguel A. Gamonal: "Con la llegada de Alberti y María Teresa León a Madrid, tras su accidentada huida de Ibiza, y el establecimiento en la sede del Palacio del Marqués de Heredia-Spínola, la Alianza se convirtió en el más importante e imponente manipulador de las conciencias y en vivero del que surgirán las ideas que nutrirán la política oficial cultural y propagandística de la España republicana" (Gamonal, 1987, p. 29). 
Trasladado a Valencia el gobierno central republicano, la Alianza de Intelectuales para la Defensa de la Cultura, su homónima a partir de enero de 1937, se instala en la nueva sede de la capital española. Allí se le fusiona la Unidad de Escritores y Artistas Proletarios, de Josep Renau, y Acción d'Art, grupo valencianista de Emilio Ots y Capdequí, entre cuyos miembros se encuentran Juan Gil-Albert, Ramón Gaya, Rafael Dieste, Antonio Sánchez Barbudo, Arturo Souto, Miguel Prieto y Antonio Rodríguez Luna (Gamonal, 1987, pp. 29-30).

El Congreso en el que se presenta la "Ponencia Colectiva" se celebra en 1937. Lo firman muchos escritores y artistas vinculados a la revista Hora de España: Arturo Serrano Plaja -que se encargó además de leerla en el congreso-, Antonio Sánchez Barbudo, Ángel Gaos, Antonio Aparicio, Arturo Souto, Emilio Prados, Eduardo Vicente, Juan Gil-Albert, José Herrera Petere, Lorenzo Varela, Miguel Hernández, Miguel Prieto y Ramón Gaya. De este grupo, sólo Souto, Vicente, Prieto y Gaya eran artistas plásticos.

Para entender la complejidad ideológica del texto y la importancia que tiene de cara a poner en pie lo que puede ser considerado una muestra de la estética española de los años treinta, hay que recordar que el congreso en el que se leyó no estuvo exento de controversia. Su organización fue capitaneada por el Partido Comunista, lo que condicionó en buena medida la elección de los conferenciantes. Pese a su declarado apoyo a la República, la izquierda antiestalinista -los trotskistas y los surrealistas- no fueron invitados, como tampoco lo habían sido en el I Congreso Internacional de Escritores para la Defensa de la Cultura de 1935, cuyo presidente de honor fue André Gide (Meyer-Minnemann, Luengo, Pérez, 2003). La ausencia de Gide del II Congreso, debida a que tampoco fue invitado por el comité organizador, originó la mayor parte de las controversias que enfangaron el famoso evento.

A pesar de que Gide se había convertido en un sincero defensor de la utopía socialista soviética, su conocimiento directo del país truncó sus expectativas. En junio de 1936, aceptó una invitación oficial del Partido para visitar, durante dos meses, la Unión Soviética. Gorki había fallecido un día antes y Gide, aprovechando la ocasión, pronunció en la Plaza Roja una oración fúnebre tras las intervenciones de Molótov, Bulganin y Alexéi Tolstói. Durante su estancia, Gide viajó a Leningrado, al Cáucaso, al Mar Negro y visitó todo tipo de instituciones, desde koljoses hasta fábricas, pasando por sanatorios, universidades y museos. Las impresiones de aquel viaje fueron anotadas en los cuatro cuadernos que compusieron poco después su libro Retour de l'U.R.S.S., publicado a principios de noviembre de 1936. En él, 
entre loas y aplausos, Gide no pasó la oportunidad de criticar determinados aspectos que, desde su perspectiva, deslucían las utopías socialistas de la Unión Soviética: la uniformidad del hombre soviético, el paradójico regreso al espíritu pequeño burgués, la persistencia de enormes diferencias sociales, la falta de libertad artística, el culto exagerado a la personalidad de Stalin, la ignorancia del pueblo soviético con respecto a todo lo que existiera fuera de la U.R.S.S. o la imposibilidad de ejercitar la crítica. La controversia estaba servida, así como también, todo hay que decirlo, el éxito de ventas. El libro llegó a traducirse a quince idiomas, entre ellas al español, lo que produjo un impacto en el Partido Comunista, tanto en España como en su país natal. Como consecuencia, Gide fue aislado del ámbito intelectual prosoviético que él mismo había liderado poco tiempo antes.

La ausencia de Gide del II Congreso de Escritores Antifascistas no puede desvincularse de este aislamiento ideológico de los defensores sin miramientos del socialismo soviético. Es posible que los organizadores obedecieran consignas o presiones de la propia delegación soviética en España para no invitar al escritor. A ello hay que sumar que, en respuesta a esta desatención generalizada, Gide editó un segundo volumen con el título de Retouches à mon Retour de l'U.R.S.S. que sale a la luz pocos días antes de comenzar el II Congreso. En este libro extiende la crítica del primero mencionando asuntos aún más turbios como los Procesos de Moscú (la Gran Purga). A raíz de esta otra publicación, en el II Congreso, se discutió ampliamente el "asunto" Gide y las opiniones fueron variopintas: José Bergamín, en nombre de la delegación española y de las delegaciones hispanoamericanas, expresó su indignación por la publicación de los Retouches e, implícitamente, también contra el Retour. Además, solicitó expresamente a los participantes del congreso que suscribieran este "reproche" y esta "repulsa" con su silencio, como indicaba en su "Reproche a André Gide" en el número 38 del El Mono Azul: "Yo os pido vuestra solidaridad con vuestro silencio para dejar que esta voz mía, precisamente por ser tan débil, vaya a unirse al silencio mismo de la sangre mártir de nuestro pueblo en Madrid para llevar a la conciencia del autor de ese libro esta repulsa y este reproche nuestro". La delegación rusa pidió la expulsión de Gide de la Alianza Internacional de Intelectuales. Algunos escritores ligados a la revista Hora de España, como Rafael Dieste, se opusieron, sin embargo, a esta desacreditación generalizada (Meyer-Minnemann, Luengo, Pérez, 2003).

Así pues, el "asunto" Gide enturbió la celebración del congreso, pero eso no impidió que en su seno se leyese la "Ponencia Colectiva", cuyas ideas 
cobran otra luz a la vista del contexto descrito. Hay que mencionar que en el escrito se abandonaba de manera grupal las coordenadas del realismo soviético ortodoxo en su dimensión estética. Es posible afirmar también que parte de las fuentes inspiradoras del texto deriva del rechazo que el propio Gide había mostrado por los dogmas del realismo socialista y sus reservas hacia el stalinismo, así como, en otro orden de cosas, a las reticencias que, en la misma línea, había hecho Malraux en el Congreso de Escritores de Moscú de 1934. Si a ello se suma que los ponentes del congreso procedían en su mayor parte del purismo poético y la "deshumanización”, que habían experimentado una clara evolución -aunque sin extremismos-, a la re-humanización del arte, y una paralela inclinación hacia la mística popular, quizás influenciada por su vivencia de las Misiones Pedagógicas, tenemos el cúmulo más favorable de factores a favor del distanciamiento artístico del realismo soviético (defendido por muchos ponentes del congreso) y de la reivindicación estética de la libertad.

¿Qué ideas planteaba, entonces, la "Ponencia Colectiva” ? Aunque de forma soterrada, en el texto se observa, en efecto, cierto distanciamiento de la política soviética para dejar paso a la defensa de la independencia intelectual; ello se hace manifiesto en las referencias implícitas al Gide de la Défense de la culture y al joven Unamuno, en sus reflexiones sobre el arte, la tradición y el humanismo. Eso no impide que en otros puntos la ideología del texto coincida con la política del Partido Comunista Español, en especial, en sus críticas al anarquismo (Meyer-Minnemann, Luengo, Pérez, 2003).

Por otro lado, frente al colectivismo propio del realismo ruso ${ }^{8}$, la "Ponencia Colectiva" se autocalifica de consciente de la individualidad de cada uno de los firmantes, lo que se remarca con el tono autobiográfico y vívido con el que se relata el conflicto entre política y arte que tanto importa en esta in-

8. Tengamos en cuenta que, en aquel momento, la idea ampliamente extendida del colectivismo era un tema controvertido, tanto artísticamente como desde un punto de vista político y social. Artísticamente, el debate alrededor del colectivismo se había intensificado a partir del I Congreso de Escritores Soviéticos de 1934, en el cual se enunciaron las líneas directrices del realismo socialista. Por contraposición, en su discurso en el I Congreso Internacional de Escritores para la Defensa de la Cultura, el mismo Gide se había pronunciado a favor del individualismo del escritor, sin que ello tuviera que suponer necesariamente el rechazo, desde el nivel político, del comunismo. En su caso, no parecía haber incompatibilidad entre una y otra cuestión. (Meyer-Minnemann, Luengo, Pérez, 2003). 
vestigación. Las contradicciones que este par les suscita a sus autores quedan claramente expresadas en el escrito:

Una serie de contradicciones nos atormentaban. Lo puro, por antihumano, no podía satisfacernos en el fondo; lo revolucionario, en la forma, nos ofrecía tan solo débiles signos de una propaganda cuya necesidad social no comprendíamos y cuya simpleza de contenido no podía bastarnos. Con todo, y por instinto tal vez, más que por comprensión, cada vez estábamos más del lado del pueblo [...] La pintura, la poesía y la literatura que nos interesaba no era revolucionaria [...] En definitiva, cuanto se hacía en arte, no podía satisfacer un anhelo profundo, aunque vago, inconcreto, de humanidad, y por otro, el de la Revolución no alcanzaba tampoco a satisfacer ese mismo fondo humano al que aspirábamos, porque precisamente no era totalmente revolucionario. La Revolución, al menos lo que nosotros teníamos por tal, no podía estar comprendida ideológicamente en la sola expresión de una consigna política o en un cambio de tema puramente formal. El arte abstracto de los últimos años nos parecía falso. Pero no podíamos admitir como revolucionaria, como verdadera, una pintura, por ejemplo, por el sólo hecho de que su concreción estuviese referida a pintar un obrero con el puño levantado, o con una bandera roja o con cualquier otro símbolo, dejando la realidad más esencial sin expresar. Porque de esa manera resultaba que cualquier pintor reaccionario -como persona y como pintor- podía improvisar, en cualquier momento, una pintura que incluso técnicamente fuese mejor y tan revolucionaria, por lo menos, como la otra, con sólo pintar el mismo obrero con el mismo puño levantado. Con sólo pintar un símbolo y no una realidad. El problema era y debía ser de fondo; queríamos que todo el arte que se produjese en la Revolución, apasionadamente de acuerdo con la Revolución, respondiese ideológicamente al mismo contenido humano de esa revolución, en la misma medida, con la misma intensidad y con igual pasión con que se han producido todos los grandes movimientos del espíritu. (AA. VV., 1937, en Aznar Soler, 1987)

$\mathrm{Ni}$ arte puro, ni arte revolucionario. Ni uno ni otro satisfacían sus inquietudes culturales. Los ponentes parecían haber quedado en un limbo estético condenado a desaparecer si no reclamaban una postura fiel a su sentir, aunque no encajara del todo en el contexto experienciado. Se trataba de encontrar una expresión artística relacionada con la revolución y la guerra, pero sin que tuviera que desembocar en el simbolismo huero impuesto por el realismo socialista, ni en el alejamiento del humanismo agotado ya por las vanguardias; $y$, sobre todo, se trataba de hallar una expresión artística comprometida, que no comprometiera a su vez su independencia intelectual e individual. Lo puro se apreciaba ya como antihumano, pero la propaganda socialista 
también, por no considerarse un arte auténticamente revolucionario y por parecer excesivamente reductor. La solución se hallaba en la creación de un arte popular, que no populista, hecho por y para el hombre como ser real, de unamuniana carne y de pasión (Bundgaard, 2009, p. 226). La ponencia terminaba, por eso, en una sentida exaltación del credo esencial del humanismo.

Es en este aspecto donde se ha querido ver una influencia más del Gide del discurso del I Congreso Internacional de Escritores para la Defensa de la Cultura, quien había advertido de la estrechez de un arte sólo orientado a las necesidades de una clase o de una época concreta (Meyer-Minnemann, Luengo, Pérez, 2003). El humanismo de Gide, como el de la "Ponencia Colectiva", aspiraba por el contrario a una "humanidad" no circunstanciada e imposible de confundir con la mera propaganda partidista y condicionada por su tiempo. Las aspiraciones de la "Ponencia Colectiva" a elevarse más allá de lo circunstancial son evidentes y permiten defender el texto, como se ha insinuado, como un auténtico manifiesto estético que trasciende su determinación histórica.

El arte por y para el hombre que se reclamaba en la "Ponencia Colectiva" tampoco excluía la tradición. Al contrario, quería aprovecharse "de todo cuanto en el mundo ha sido creado con esfuerzo y clara conciencia, para, esforzadamente, enriquecer [...] esa claridad creciente del hombre" (AA. VV., 1937, en Aznar Soler, 1987). Por eso, alusiones a figuras de la tradición artística española no faltan en el texto: "Hoy, al menos así lo entendemos nosotros, la voluntad quiere exactamente aquello que la razón exige, porque, a su vez, la razón precisamente por razón, sólo exige la voluntad, la buena voluntad de Sancho Panza, cuando esta está ya quijotizada, cuando ya también Sancho quiere aventuras” (AA. VV, 1937, en Aznar Soler, 1987).

En definitiva, los firmantes se calificaban y se reconocían básicamente con una sola palabra: humanistas, entendiendo el calificativo como ideología que restituye al hombre su valor esencial. Para terminar este apartado de la investigación, conviene, así, citar la propia definición de humanismo que plasman los ponentes en el escrito:

El humanismo que defendemos, el que nace ahora en España, es, por excluir todo eso más amplio que el otro, y, por su lucha, verídico, viril, renovador, heroico. Es un humanismo, en todo caso, cuya definición exacta y, por decirlo así, teórica, no puede hacer sino en la medida misma que se producen ciertos hechos empíricos, vivos y varios que son los que realmente decimos. Porque vive de realidades y de supuestos, su existencia misma depende de la existencia del hombre como hombre, esto es, liberado de todo cuando no sea 
una confección del mundo en la que el hombre es, ciertamente, el valor esencial. Hecho hoy tan ligado a la batalla del pueblo español, como expresión de voluntad razonable, tiene existencia y cuyo mayor o menor desarrollo, se podrá establecer y discutir sólo con el triunfo definitivo de nuestro pueblo. De este humanismo implicado así en nuestra lucha, nos consideramos nosotros activos militantes. Y ponemos la contribución, para afirmarlo, cuando nos es dable: desde nuestra voluntad a nuestra juventud, entendida esta última, no como una abstracción parada, estática; no como juventud afirmada tan sólo en un hecho cronológico y por lo tanto anacrónica, "viejo", sino como posibilidad de esfuerzo y de acción. (AA. VV., 1937, en Aznar Soler, 1987)

\section{El compromiso artístico-espiritual de Ramón Gaya}

Como ya se ha comentado, Ramón Gaya no es en absoluto ajeno a la desacreditación de la vanguardia y a la politización del arte que tienen lugar en el contexto prebélico español. Desde el comienzo, su postura será en este aspecto de marcado carácter purista, en el sentido de que, pese a entender que los artistas deben implicarse en la sociedad, también han de preservar "limpio" el arte. En este apartado de la investigación, el objetivo consiste en abordar los argumentos fundamentales que el pintor murciano elaboró para sostener esta postura estética y conciliarla con su compromiso político "material". Para ello, se repasarán muchas de las ideas vertidas en ensayos fundamentales de su producción, así como entrevistas y otros testimonios valiosos, a fin de situarlos en relación con el contexto histórico ya reseñado.

Una de las principales razones por las que Gaya se muestra tan cauteloso frente a lo que se puede denominar, en un sentido amplio, "arte comprometido", deriva de su convicción de que "lo social" no ha nacido de forma natural, sino que ha sido inventado por el hombre, y de que toda invención es una realidad postiza, falsa y superpuesta: "El invento es una mentira que ha llegado a hacerse corpórea, incluso real, pero que no logra nunca hacerse verdad” (Gaya, 1990, p. 83). Para Gaya, “lo social” es una mecánica en la que se ha acoplado al hombre y en el seno de la cual ha nacido la dudosa idea de “justicia”. El pintor desconfía porque cree que la justicia, más que salvar al hombre, lo que hace es proteger la propia mecánica, instaurar la mediocridad y convertirse, finalmente, en una abstracción en la que el ser humano se limita a ejercer la función de artefacto servil ${ }^{9}$. Esta abstracción es paralela a la

9. "La justicia es la exaltación de la mediocridad -por eso Dios nos la regatea tanto, 
que se achacaba, en la "Ponencia Colectiva", a la propaganda soviética, que a lo más que llegaba era al simbolismo vacío de una comunidad, exento de verdadero sentimiento o pasión.

En los escritos de Gaya, también se pueden encontrar opiniones diversas en torno a la imposibilidad de que el arte sea colectivo o tenga un sentido social, aunque temática o iconográficamente lo posea (Gaya, 1975). La creación verdadera sólo es posible si el "centro" del hombre no se encuentra aún en la sociedad, sino en su estado primigenio y primitivo que es anterior a la historia y la cultura, los ámbitos en los que se desarrolla el sentido político o cívico. Gaya acepta que existan obras de contenido ideológico, pero sólo en la medida en que su temática sea tomada como anecdótica, es decir, en la medida en que no obstaculice la transparencia del arte en su desnudez (Gaya, 1990, p. 84). La creatividad puesta al servicio de las ideas, las colectividades o la política es siempre menor, puesto que subordina su fidelidad a la esencia o principio de la creación a cuestiones e intereses extra-artísticos. La consecuencia que se sigue es que el arte comprometido se convierte en "cartel”, lo que para Gaya es sinónimo de “pintura decorativa” (citado en Dennis, 2011). Pese a que comprende que en época de guerra los artistas deben colaborar en la propaganda, opina que a sus productos no se les debe calificar de artísticos, puesto que eso "sería olvidar que, aunque sean artistas geniales los dedicados a ella, lo que se emplea de estos artistas no es su arte, no es su genio, sino su facilidad técnica” (Gaya, 1975, p. 286). El artista puede, e incluso debe, poner su destreza al servicio del poder, pero el producto que de sus manos se extraiga no ha de considerarse verdadera creación. El arte comprometido es un medio, nunca un fin, y el artista debe saber que cualquier inversión de esta máxima niega la pureza estética. El arte sólo es verdadero cuando se muestra fiel a su esencia primordial, a su desnudez, que trasciende cualquier finalidad o interés práctico, político o social.

En lugar de exigir un arte comprometido, para los períodos de guerra, Gaya se inclina por un arte verdadero, intenso, emocional, pasional, de "carne" y de "vida” (Gaya, 1975, p. 286). De ahí que el papel del artista en un contex-

para que la mediocridad no pueda reinar en el mundo despóticamente-, y ¿cómo vamos a suponer que la mediocridad puede salvar al hombre? Podrá tirar de él, atraparlo, conquistarlo, y una vez allí, taparlo con un poco de felicidad humillante; pero el artista no se puede interesar por nada que no sea naturaleza, porque para él, todo lo que no es naturaleza es mentira, aunque sea una mentira remediadora, como viene a ser lo social" (1990, p. 83). 
to político conflictivo se parezca menos al del comprometido implicado, que al del espectador que registra en la distancia la barbarie:

El artista verdadero no es que deba, sino que está siempre atento a eso que llaman su tiempo: los poderes, la política, la sociedad. Pero está allí no para intervenir en eso que se traen los poderes o la sociedad, sino como observador de esos fenómenos. (Citado en Dennis, 2011, p. 289).

La propuesta contraria al arte comprometido es, pues, para Gaya, la del arte verdadero, emocional, pasional, que haga estremecer, en un sentido muy cercano a lo expuesto en la "Ponencia Colectiva". Los ejemplos que el pintor murciano tiene en la cabeza hablan por sí solos: Goya, Delacroix, Gutiérrez Solana, Honoré Daumier, pintores de momentos políticamente delicados, que sin embargo priorizaron el sentimiento al compromiso ideológico declarado; o, también se podría decir, que mostraron su compromiso desde el lado estrictamente pasional, sin sucumbir a los reduccionismos e indiferencias sentimentales del arte propagandístico en sus diversas formulaciones. De ahí la universalidad de sus propuestas, su aspiración a concernir, no a facciones partidistas determinadas, sino a la entera humanidad.

En sus más conocidos escritos sobre arte, es notorio que a Gaya le interesa priorizar metafóricamente el valor de la naturaleza sobre el arte con minúscula (arte entendido como techné, técnica o artificio, en sentido amplio), e incluso hacer derivar al segundo del primero. No por casualidad, Gaya va a defender que es la realidad la que quiere ser escuchada, y no el arte el que la fuerza a hablar, y que, para ello, la propia naturaleza propone al hombre algunos senderos a través de los cuales manifestarse: la poesía, la pintura, la escultura y la música, cada uno ligado por origen a distintos elementos primordiales, aire, agua, tierra y fuego. En esa prioridad natural descansa la idea del vasallaje o la obediencia del artista, que tan importante resulta para entender la aparente contradicción entre destino y libertad en el caso de Ramón Gaya. El pintor defiende que el creador está "sometido", que constituye un "vasallo" o un "siervo" del sentimiento que le corresponde. Inevitablemente, desde la postulación de la dependencia que el arte tiene de la naturaleza, el artista no puede sino ser un esclavo de ella -también llamada en ocasiones "realidad"- y ser esclavo por extensión de lo que a ella la "salva", el Arte (ahora ya con mayúsculas). El vasallaje del artista brota además del sentimiento, porque, según el pintor, éste es “obediente, apegado a su raíz” (Gaya, 1990, p. 38), y porque, frente al entendimiento, se humilla ante lo real. Existe por 
eso una especie de "voz" que exige al artista crear "sin remedio" (Gaya, 1996, p. 18). Como dice Gaya, que el arte se produzca es una necesidad que proviene de una "primaria y tiránica energía del hombre como especie pura, bruta" (Gaya, 2002, p. 20). En consecuencia, lo que hace el creador no es tanto una tarea o una aportación o servicio, sino una especie de "sacrificio". El artista concebido por Gaya se convierte así en un individuo creador, pero involuntario, que sigue su destino y que, gracias a eso -he aquí la paradoja con la que comenzó este artículo-, se vuelve libre de verdad. Un párrafo muy citado de Gaya ilustra magistralmente la idea:

El arte es Destino, y el día que esto se llegue a comprender dejaremos de oír todo ese estúpido rosario de obligaciones que los diferentes estetas le han echado siempre encima-que el arte debe ser bello, o moral, o expresivo, o imaginativo, o copiador, o abstracto-, y se caerá en la cuenta de que el arte, como destino que es, no lo podemos construir nosotros, ni siquiera hacerlo nosotros, sino escucharlo y cumplirlo. (Gaya, 1990, p. 68).

Volviendo a una idea de Orden Jiménez con la que se inició esta investigación, puede afirmarse que la actitud de Ramón Gaya ante el arte en plena crisis política y social es susceptible de interpretarse a la luz de las palabras que Nietzsche expresa en La gaya ciencia para aunar la idea de la vocación o destino del artista y el lema de raigambre estoica del amor fati: “¿Qué dice tu conciencia moral?”, se pregunta, es decir, cuál es la vocación o compromiso: "Debes llegar a ser el que eres", responde siguiendo al poeta, esto es, hay que asumir el destino (Orden, 2011). La diferencia sería que Gaya no concebía la relación del destino y la vocación de modo individual, sino, por influencia de su propia experiencia comunitaria en las Misiones Pedagógicas y del humanismo suprapartidista y supraindividual, profesado en textos emblemáticos como la "Ponencia Colectiva”, entendía esa relación, insistimos, de modo social o, como diríamos hoy, de manera política. Eso quiere decir que, en su caso, el destino estaría asociado a la vida del pueblo y, por ello, la vocación sería siempre vocación común, si no popular o predestinación única e identitaria para un pueblo. Para Orden Jiménez, esto es, en realidad, un rasgo del estoicismo español característico de todos aquellos intelectuales que, durante el siglo XIX y primer tercio del XX, trabajaron por la reforma del país. Gaya escribía con y desde una intensa y desgarradora experiencia personal, pero compartida con compatriotas que atravesaron circunstancias muy similares 
y que contribuyeron a extender entre su generación la idea de comunidad en la adversidad. Pero Gaya escribía también bajo el horizonte más general de la tradición española del krausoinstitucionismo (Moreno, 2018), que supo identificar el destino individual dentro del destino nacional y que todavía aspiraba a la generalidad en las cuestiones relacionadas con la ética, la política y la estética. Por eso llegó a sentir su exilio, como bien indica Orden Jiménez, como lealtad última y resultado mismo de su compromiso y vocación pictórica de carácter supraindividual (Orden, 2011).

Pintar, entonces, era también su forma de comprometerse políticamente, pero pintar bajo las consignas partidistas de una sola facción, por muy identificado que pudiera sentirse "materialmente" con ella, no podía ser lo mismo que pintar bajo el auspicio del sentimiento, que, desde la Ilustración, había sido definido como común al género humano. El sensus communis aestheticus, teorizado desde Shaftesbury hasta Kant, encontraba así un hueco, se podría afirmar, quizás no tanto en la teoría como en la práctica artística de toda una generación. Por decirlo en términos del propio Gaya, el arte fluye, cual el agua, desde más allá de esas posiciones políticas circunstanciales; es en realidad el manantial del propio sentimiento y, por eso, es posible decir que es previo pero se sitúa también al final, como objetivo último o finalidad (¿sin fin? ¿ del arte?); eso quiere decir que lo que queda en medio, que no son más que manifestaciones provisionales, es polvo y se desvanece. No se puede ser vasallo de lo que apenas pervive. La libertad está en el compromiso con lo único verdadero y esencial.

\section{REFERENCIAS BIBLIOGRÁFICAS}

AA. VV. (2018). Y así nos entendimos. Correspondencia entre María Zambrano y Ramón Gaya. Valencia: Pretextos.

Aznar Soler, M. (1987). Congreso Internacional de Escritores para la Defensa de la Cultura (Valencia-Madrid-Barcelona-París, 1937). Vol. II: Literatura española y antifascismo (1927-1939). Valencia: Generalitat Valenciana, Conselleria de Cultura, Educació y Ciencia.

Ballester, J. (2007). "Joseph Renau. Pro arte impura”, en AA. VV. Josep Renan (1907-1982). Compromiso y cultura. Universitat de València y Sociedad Estatal de Conmemoraciones Culturales (SECC), pp. 234-245.

BundgaARD, A. (2009). Un compromiso apasionado: María Zambrano: una intelectual al servicio del pueblo (1928-1939). Madrid: Trotta. 
Cano Ballesta, J. (1972). La poesía española entre pureza y revolución (1930-1936). Madrid: Gredos.

Совв, C. H. (1992-93). “El Agit-Prop Cultural en la Guerra Civil”. Studia Historica-Historia Contemporánea, X-XI, pp. 237-249.

Dennis, N. (2011). “Ramón Gaya y el Museo del Pueblo de las Misiones Pedagógicas”. Escritura e imagen, 7, pp. 15-26.

Gamonal Torres, M. A. (1987). Arte y politica en la guerra civil española. El caso republicano. Granada: Diputación Provincial de Granada.

Gamonal Torres, M. A. (2014). “Arte de urgencia: aportaciones al debate crítico sobre el arte de propaganda en la Guerra Civil española”. Cuadernos de Arte de la Universidad de Granada, 45, pp. 169-190.

Gaya, R. (1975). “Cartas bajo un mismo techo”, en Caudet, F. (ed.). Hora de España (Antología). Madrid: Turner.

GAyA R. (1990). Obra completa. Tomo I. Valencia: Pre-textos.

GAYA, R. (2002). Naturalidad del arte (y artificialidad de la crítica). Valencia: Pretextos.

Gaya, R. (2002). Obra completa. Tomo II. Valencia: Pre-textos.

MARín ECED, T. (1990). La renovación pedagógica en España (1907-1936). Los pensionados en pedagogía por la Junta para Ampliación de Estudios. Madrid: CSIC.

Meyer-Minnemann, K., Luengo, A., Pérez y Effinger, D. (2003). "La Ponencia Colectiva (1937) de Arturo Serrano Plaja: una toma de posición literaria y política en la Guerra Civil”. Revista de Literatura (CSIC), LXV, 130, pp. 447-469.

Moreno, M. (2018). Otra modernidad. Estudios sobre la obra de Ramón Gaya. Valencia: Pre-textos.

Murcia Serrano, I. (2010). Agua y destino. Introducción a la estética de Ramón Gaya. Oxford: Peter Lang.

ORden JiméneZ, R. (2011). “Ramón Gaya, vocación y destino del artista Ramón Gaya”. Escritura e imagen, 7, pp. 11-14. 